\title{
HABERMAS: \\ LEGITIMIDAD Y \\ DISCURSO \\ PRÁCTICO
}

Enrique Serrano*

Para Habermas en la discusión en torno a la legitimidad está en juego la posible fundamentación de las cuestiones práctico-morales. Habermas reconoce que la definición empírica de la legitimidad es de gran utilidad en las investigaciones sociológicas. Sin embargo, él ve también que en esta definición hay una pérdida de la capacidad de argumentar racionalmente sobre los criterios de validez que intervienen en los procesos de legitimación. "La permuta empirista de la legitimación por aquello que se tiene por tal permite, pues, investigaciones sociológicas plenas de sentido... De todas maneras parece legítimo preguntarse por el precio que el empirista ha de pagar por la redefinición de su objeto. Cuando se entiende el ámbito objetual de modo tal que en su interior no puedan aparecer órdenes legítimos, sino tan sólo órdenes tenidos por tales, se ciega en el análisis el nexo existente entre las razones y los motivos; y en todo caso se excluye, por razón de método, una valoración de las razones independientes del actor. El estudiosos mismo se abstiene del enjuiciamiento sistemático de las razones en las que se apoyan las pretensiones de legitimidad." ${ }^{1}$

Cuando nos limitamos a dar una definición empírica de la legitimidad adoptamos la postura de observadores, ocupados únicamente en cons-

\footnotetext{
${ }^{*}$ Universidad de Constanza, Alemania.

${ }^{1}$ Habermas, La reconstrucción del materialismo histórico (RMH), Taurus, Madrid, 1981, p. 266. Zur Rekonstruktion des historischen Materialismus (RHM), Suhrkamp, Frankfurt, 1976, p. 293.
} 


\section{Enrique Serrano}

tatar que la pretensión de legitimidad de un orden es reconocida de facto en un contexto social y tiempo determinado. Frente a esta postura Habermas destaca que el reconocimiento de la legitimidad está motivado, entre otras cosas, por apelar a razones y que la validez de estas razones sólo puede juzgarse si se abandona la posición de observador externo al proceso de legitimación. "Ahora bien: que las razones sean buenas razones es algo que sólo se pude establecer en la actitud perfomativa de quien participa en una argumentación, no en virtud de la observación neutral de aquello que éste o aquel participante en un discurso considera como buenas razones." 2

La intención de Habermas es desarrollar una "Teoría Crítica". Ésta no puede conformarse con una descripción de las diferentes formas de legitimaicón, sino que debe preguntar por un posible criterio normativo que nos permita juzgar las pretensiones de validez de aquéllas. Habermas retoma el reto de dar una definición normativa de la legitimidad. Lo interesante de este proyecto es que no pretende "reencantar" el mundo; por el contrario, asume tanto la crítica a las visiones tradicionales del mundo, como el reconocimiento de la pluralidad que caracteriza a las sociedades modernas. "Hasta ahora he analizado dos conceptos de legitimación: el empirista y el normativo. El primero es aplicable, hablando en lo que a las ciencias sociales antañe, mas resulta insatisfactorio por cuanto hace abstracción de una ponderación sistemática de los fundamentos de la validez. El otro concepto, que sería satisfactorio en este sentido, resulta empero, insostenible a causa del contexto metafísico en que se encuentra enmarcado. Por todo ello, lo que yo propongo es un tercer concepto de legitimación, que me atrevería a calificar de reconstructivo." ${ }^{3}$

Veamos esta definición de legitimidad, para después examinar en que consiste su carácter de "tercera" posibilidad. "Legitimidad significa que la pretensión que acompaña a un orden político de ser reconocido como correcto y justo no está desprovista de buenos argumentos; un orden legítimo merece el reconocimiento. Legitimidad significa el hecho del

\footnotetext{
${ }^{2}$ Habermas, RMH, p. 266. RHM, p. 294.

${ }^{3}$ Habermas, $R M H$, p. 270. RHM, p. 298.
} 
LEGITIMIDAD Y DISCURSO PRÁCTICO merecimiento de reconocimiento por parte de un orden político." Más adelante agrega Habermas: "Por legitimidad entiendo el hecho de que un orden político es merecedor de reconocimiento. La pretensión de legitimidad hace referencia a la garantía -en el plano de la integración social- de una identidad social determinada por vías normativas. Las legitimaciones sirven para hacer efectiva esa pretensión, esto es: para mostrar cómo y porqué las instituciones existentes (o las recomendadas) son adecuadas para emplear el poder político en forma tal que lleguen a realizarse los valores constituidos de la identidad social."4

La intuición inicial de Habermas es que la legitimidad de un poder está vinculada indisolublemente a un proceso de comunicación. El poder tiene, en tanto es un fenómeno social, una realidad simbólica; de ahí proviene su necesidad de justificación y también ahí se encuentran los medios de esta justificación.

El derecho natural ya había localizado la fuerza legitimante en la formación de un consenso racional. Pero la tradición del jusnaturalismo no se había conformado con mantener al consenso como sostén de la legitimidad, sino que, en casi todas sus versiones existe la tendencia a dar un contenido específico a ese consenso. En cambio Habermas busca llevar hasta sus últimas consecuencias la sustitución de las razones últimas, por las condiciones formales de un consenso racional. "Por niveles de justificación entiendo, pues, condiciones formales de la aceptabilidad de las razones que prestan a las legitimaciones eficacia, fuerza consensual y fuerza motivadora... Fuerza legitimante hoy sólo la poseen reglas y premisas comunicativas, que permiten distinguir un acuerdo o pacto obtenido entre personas libres e iguales frente a un consenso contingente o forzado." 5

Para Habermas el núcleo normativo de la legitimidad se encuentra en las condiciones pragmáticas que permiten la comunicación entre los individuos dentro del proceso de legitimación. La tesis fundamental consiste en afirmar que el lenguaje tiene como "telos" interno el entendimiento (Verständigung). A partir de esta tesis se proponen otras dos

\footnotetext{
${ }_{5}^{4}$ Habermas, $R M H$, p. 243 y $249 . R H M$, p. 271 y 276.

${ }^{5}$ Habermas, $R M H$, p. 251 y $254 . R H M$, p. 278 y 281.
} 


\section{Enrique Serrano}

complementarias: 1. En el concepto de entendimiento se encuentra implícito la idea de un acuerdo libre de coacción y 2. El concepto de entendimiento presupone una noción amplia de racionalidad. Con estas tesis se apunta la estrategia de fundamentación de una noción normativa de legitimidad que no tiene que recurrir a un orden trascendente (divino, natural o histórico). Ahora se plantea que son las condiciones que permiten acceder a un acuerdo racional las que poseen una fuerza legitimante y que estas condiciones se encuentran implícitas en todo proceso de comunicación lingüística. Por tanto, se trata de reconstruir los procesos de comunicación para determinar esas condiciones.

Habermas denomina a su concepto de legitimidad como "reconstructivo", ello hace referencia al método en que ese concepto se sustenta. El objetivo del llamado "método reconstructivo" es hacer explícitos los elementos y estructuras de saber preteórico, presentes en las acciones humanas. ${ }^{6}$ Examinemos algunos aspectos generales de este método para precisar el sentido del concepto "reconstructivo" de legitimidad.

Habermas se remite a los trabajos lingüísticos de Chomsky. Este último distingue entre "ejecución lingüística efectiva" (performance) y competencia lingüística (competence). Mientras la primera se refiere al uso del lenguaje en situaciones particulares, la segunda se refiere a los principios lingüísticos (fonéticos, sintácticos y semánticos) que debe asumir cualquier "hablante-oyente" en el uso del lenguaje. 7 Para Chomsky el objeto teórico de la lingüística no es el habla efectiva (performance), sino los principios a los que debe recurrir un hablante competente de una lengua (competence). La forma de acceder a estos principios que asume todo hablante competente es a través de una reconstrucción de los procesos lingüísticos, que tiene por objetivo distinguir los aspectos empíricos y contingentes de dichos principios, a los que Chomsky considera como "universales lingüísticos".

Por su parte Habermas sostiene que no sólo los rasgos fonéticos sintácticos y semánticos de las oraciones, sino también ciertos rasgos de

${ }^{6}$ Ver: Habermas, Zur Logik der Sozialwissenschaften, Suhrkamp, Frankfurt, 1982. McCarthey, La Teoria Crítica de Jürgen Habermas, Tecnos, Madrid, 1987.

${ }^{7}$ Chomsky, Aspectos de la teoria de la sintaxis, Aguilar, Madrid, 1970. 
LEGITIMIDAD Y DISCURSO PRÁCTICO las emisiones admiten una reconstrucción en términos universales. En otras palabras no sólo la lengua ("competencia lingüística"), también el habla ("competencia comunicativa") es susceptible de una reconstrucción racional. ${ }^{8}$ en el acto del habla el hablante no sólo emite una oración con un contenido empírico ("O"), también la situa pragmáticamente a través de un "modo" (fuerza ilocucionaria), por ejemplo, "te prometo que o", "te exigo o", "te aseguro que o", etc. La encargada de reconstruir las estructuras generales que aparecen en todo acto del habla es la "pragmática universal".

"He propuesto el nombre de pragmática universal para el programa de investigación dirigido a la reconstrucción de las bases universales de validez de habla... La intención básica de la pragmática universal de los actos del habla se expresa en el hecho de que tematiza las unidades elementales del habla (emisiones) en la misma actitud que la lingüística tematiza las unidades del lenguaje (oraciones). La meta del análisis reconstructivo del lenguaje es la descripción explícita de las reglas que un hablante competente debe dominar para formar oraciones gramaticales y emitirlas de forma aceptable. La teoría de los actos del habla comparte esta tarea con la lingüística. Mientras que esta útlima parte del supuesto de que todo hablante adulto posee un conocimiento implícito reconstruible, en el cual se expresa su competencia en reglas lingüísticas (para producir oraciones); la teoría de los actos del habla postula una competencia de reglas comunciativas correspondientes, a saber, la competencia de usar oraciones en actos del habla. Se supone además que la competencia comunicativa tiene un núcleo tan universal como la competencia lingüística. Una teoría general de las acciones de habla describiría, por tanto, exactamente aquel sistema fundamental de reglas que dominan los sujetos adultos en tanto que pueden satisfacer las condiciones de un empleo afortunado de oraciones en emisiones, con

\footnotetext{
${ }^{8}$ Esto es a lo que se ha denominado el "giro pragmático" que tiene sus bases en las teorías de Wittgenstein, Austin y Searle. Wittgenstein, Philosophische Untersuchungen, Suhrkamp, Frankfurt, 1984. Austin, Cómo hacer cosas con palabras, Paidós, Barcelona, 1982. Searle, Actos de habla, Cátedra, Madrid, 1980.
} 


\section{Enrique Serrano}

independencia del lenguaje particular al que esas oraciones pertenezcan y de los contextos contingentes en los que se insertan los enunciados."

El objetivo de la pragmática universal es identificar y reconstruir las condiciones unviersales de un posible entendimiento entre los sujetos sociales. Habermas sostiene que estas condiciones contienen un núcleo normativo. Toda comunicación se encuentra ligada (implícita o explícitamente) a "pretensiones de validez", estas son las siguientes: 1. Entendimiento (el cual exige que las emisiones del hablante sean inteligibles); 2. Verdad (la cual exige que los contenidos proposicionales o presuposiciones existenciales sean verdaderas); 3 . Veracidad (la cual exige que el hablante sea sincero o veraz) y 4 . Correción o Rectitud (la cual exige que la emisión sea correcta en términos morales). Estas pretensiones de validez nos remiten a las funciones pragmáticas del habla, las cuales, a su vez, nos permiten dar una clasificación de los actos del habla:

1) La primera de estas funciones es la "representativa", ella se refiere a la relación con un mundo objetivo "externo" (Verdad). Corresponde a los actos del habla "constativos".

2) La segunda es la "expresiva" y se refiere a la relación con el mundo subjetivo (Veracidad). Corresponde a los actos del habla "expresivos".

3) La función "interactiva" es la tercera y nos remite a la relación con otros individuos, es decir, con el mundo social (Corrección o Rectitud). A ella corresponden los actos del habla "regulativos".

Hasta ahora no hemos hablado del "entendimiento", ello se debe a que esta pretensión de validez es común a todos los actos del habla. Mientras que las otras pretensiones de validez relacionan la emisión del hablante con un orden extralingüístico (con el mundo externo, con el mundo subjetivo o con el mundo social), el entendimiento, en cambio, es una

${ }^{9}$ Habermas, "Was hei $\beta$ t Universalpragmatik?" (1976), Vorstudien un Ergänzungen zur Theorie des Kommunikativen Handelns, Suhrkamp, Frankfurt, 1984, p. 357 y $386-396$. 


\section{LEGITIMIDAD Y DISCURSO PRÁCTICO} pretensión inmanente al lenguaje en sus diversos usos. "La meta del entendimiento es acceder a un acuerdo que tiene como término una comunidad intersubjetiva de comprensión recíproca, de saber compartido, de confianza mutua y de coincidencia. El acuerdo se basa en el reconocimiento de las cuatro pretensiones de validez correspondientes: Entendimiento, Verdad, Veracidad y Rectitud. Podemos observar que la expresión alemana "Verständigung" (también la española "Entendimiento"- E.S.) es ambigua. Su sentido mínimo indica que dos sujetos entienden una epxresión lingüística de la misma manera. Su sentido máximo es que entre ambos existe un acuerdo relativo a la rectitud de un enunciado en relación a un contexto normativo mutuamente reconocido. Adicionalmente, dos participantes del proceso comunicativo pueden llegar a una comprensión sobre algo en el mundo y pueden hacerse mutuamente comprensibles sus intenciones. Si el pleno acuerdo, que engloba los cuatro componentes mencionados, fuera el estado normal de la comunicación lingüística, no sería necesario analizar el proceso de comprensión desde la perspectiva dinánica del producir un acuerdo." ${ }^{10}$

La acción comunicativa trascurre sobre el transfondo de un acuerdo problemático; los sujetos aceptan de manera ingenua o inmediata las pretensiones de validez inscritas en los actos del habla. Pero en cuanto una de estas pretensiones de validez se ve cuestionada la acción comunicativa queda bloqueada. Si los individuos desean mantenerse en el nivel comunicativo, deben entonces hacer explícitas estas pretensiones de válidez para restablecer el entendimiento, mediante la redefinición común de la situación. Es por ello que Habermas plantea el acuerdo, en tanto meta del entendimiento, desde una perspectiva dinámica. Cada una de las cuatro pretensiones de validez puede ser objeto de un desempeño (Einlösung) dentro de un contexto de interacción social en el que se busca justificarlas o fundamentarlas. En el caso de la verdad y la rectitud su fundamentación puede requerir salir del contexto de la acción y pasar a una situación discursiva. En el "discurso" se busca apoyar estas pretensiones de validez con argumentos. ${ }^{11}$

${ }^{10}$ Habermas, "Was hei $\beta$ t Universalpragmatik?", p. 355.

11 Habermas, "Wahrheitstheorien" (1972), Vorstudien und Ergänzungen zur Theorie des kommunikativen Handelns. 


\section{Enrique Serrano}

El discurso representa una ruptura de la acción comunicativa para acceder a un plano en el que todos los participantes deben someterse a la dinámica de la argumentación, con la finalidad de llegar a un acuerdo sobre la validez de las pretensiones cuestionadas. El discurso es una continuación por otros medios (los argumentos) de la acción orientada al entendimiento. Mediante el discurso se prueba el carácter objetivo de la verdad de las emisiones y de la corrección de las normas. El resultado del discurso racional debe ser, según Habermas, un acuerdo válido no sólo para sus participantes, sino también para todo sujeto racional posible. "Llamamos, ciertamente, racional a una persona que en el ámbito de lo cognitivo-instrumental expresa opiniones fundadas y actúa con eficiencia; sólo que esa racionalidad permanece contingente si no va a su vez conectada a la capacidad de aprender de los desaciertos, de la refutación de hipótesis y del fracaso de las intervenciones en el mundo. El medio en que estas experiencias negativas pueden elaborarse productivamente es el discurso teórico, es decir, la forma de argumentación en que se convierten en tema las pretensiones de verdad que se han vuelto problemáticas. Llamamos racional a una persona que puede justificar sus acciones recurriendo a las ordenaciones normativas vigentes. Pero sobre todo llamamos racional a aquél que en un conflicto normativo actúa con lucidez, es decir, no dejándose llevar por sus pasiones ni entregándose a sus intereses inmediatos, sino esforzándose por juzgar imparcialmente la cuestión desde un punto de vista moral y por resolverla consensualmente. El medio en que puede examinarse hipotéticamente si una norma de acción, esté o no reconocida de hecho, puede justificarse imparcialmente, es el discurso práctico, es decir, la forma de argumentación en que se convierten en tema las pretensiones de rectitud normativa." 12

La descripción del discurso como un proceso de fundamentación racional de las pretensiones de validez, en donde sólo debe aceptarse la coacción del mejor argumento, es, evidentemente, una idealización. El

${ }^{12}$ Habermas, Teoría de la acción comunicativa (TAC), Taurus, Madrid, 1987, Tomo I, p. 38. Theorie des kommunikativen Handelns, (TKH), Suhrkamp, Frankfurt, 1981, B. I, p. 39. 
LEGITIMIDAD Y DISCURSO PRÁCTICO propio Habermas afirma que el discurso es una forma de comunicación infrecuente o rara, por tratarse de un proceso que ha de aproximarse suficientemente a condiciones ideales. En este punto se introduce el conocido y muy discutido concepto de una "situación ideal de habla". Con este concepto Habermas busca hacer explícitas las condiciones que deben satisfacerse para que se dé una argumentación plenamente racional. Entre estas condiciones se encuentra la de que los participantes de una comunidad de diálogo deben reconocerse recíprocamente como interlocutores con los mismos derechos. Cada uno debe tener el derecho de exponer sus argumentos y la obligación de escuchar los ajenos, así como la de respetar la lógica de la mejor argumentación. Habermas es consciente del carácter irreal de esta situación ideal de habla; sin embargo, él mantiene que no se trata simplemente de un ideal abstracto, sino que dicha situación ideal es una suposición que subyace a todo discurso. Cualquier individuo que entre en un discurso debe aceptar implícitamente la posibilidad de llegar a un acuerdo a través de la argumentación racional. Rechazar este supuesto sería desvirtuar el sentido del proceso de argumentación.

Por otra parte, Habermas afirma que esta situación ideal de habla también ha tenido una influencia en la vida política de nuestras sociedades. El principio de que la legitimidad racional se encuentra en el diálogo que busca un acuerdo es inseparable de la historia de la democracia. Como apunta Albrecht Wellmer: "De ahí que el principio de lo razonable para la ilustración, pueda interpretarse como una demanda de abolición de todas las relaciones de poder que no tuvieran más legitimidad que la de su facticidad. La razón no como un concepto opuesto al de autoridad, sino como un principio de comunicación pacífica y no forzada, frente a la realidad experimentada de una comunicación desfigurada de la política." ${ }^{13}$ El interés por estudiar la influencia del ideal de formación racional de la voluntad colectiva en la política está presente ya en los primeros trabajos de Habermas ${ }^{14}$ y es una línea de investigación que recorre toda su producción teórica.

${ }^{13}$ Wellmer, Teoría crítica de la sociedad y positivismo, Ariel, Barcelona, 1979, p. 51 .

${ }_{14}$ Habermas, Strukturwandel del Öffentlichkeit, Darmstadt un Neuwied, 1962. 


\section{Enrique Serrano}

Esta primera aproximación a la teoría de la acción comunicativa de Habermas nos permite precisar el sentido de su definición de legitimidad. Ahora podemos acudir al siguiente razonamiento: 1. La legitimación puede conceptualizarse como un proceso de comunicación. 2. El uso comunicativo del lenguaje tiene como objetivo interno la búsqueda del entendimiento. 3. Por tanto, la legitimidad estará dada por las condiciones que permiten un proceso comunicativo orientado hacia el entendimiento. 4. Como discurso práctico la legitimidad presupone la idea normativa de una argumentación libre de toda coacción externa, en la que se ponga a prueba la validez de los fundamentos del poder.

Lo que no debemos perder de vista es algo que el propio Habermas destaca, a saber: Entre el entendimiento en su sentido mínimo y el entendimiento en su sentido máximo existe un abismo. Dos sujetos entienden una expresión lingüística porque entre ellos hay una coincidencia respecto al significado (uso) de las palabras. Pero ello, como lo vio Wittgenstein, ${ }^{15}$ no implica una coincidencia de opiniones. Un fascista y un demócrata pueden entender cada uno el sentido lingüístico del discurso del otro, pero ello no implica que puedan compartir sus opiniones. La tesis de Habermas consiste en afirmar que el entendimiento lingüístico mínimo contiene un núcleo normativo, en el cual se exige del hablante-oyente que asuma la responsabilidad de buscar un entendimiento en su acepción máxima. Es decir, que fundamente racionalmente la pretensión de verdad y corrección inscrita en sus emisiones lingüísticas. El fascista y el demócrata tendrían, para cumplir con las exigencias de ese núcleo normativo, que someter sus respectivas visiones particulares del mundo a la coacción del mejor argumento. Es evidente que de esta manera se avanzaría un gran trecho en el camino del entendimiento. ${ }^{16}$

Theorie und Praxis, Suhrkamp, Frankfurt, 1978. Arbeit, Erkenntnis, Fortschritt (Afätze 19541970), Verlag de Munter Amsterdam, Amsterdam, 1970.

15 "Correcto y falso es lo que los hombre dicen; y los hombres concuerdan en el lenguaje. Esta no es una concordancia de opiniones, sino de formas de vida." Wittgenstein, Op. cit., fragm. 241.

16 Tendríamos que examinar con más cuidado qué significa la pretensión de corrección para las pretensiones normativas. Éste es un punto esencial para hablar de un entendimiento pleno. Pospongo esta tarea, ya que ella requiere de un examen más detallado de la teoría de la acción comunicativa. 


\section{LEGITIMIDAD Y DISCURSO PRÁCTICO}

Entre sujetos racionales puros (o casi) la meta del entendimiento sería, obviamente, más fácil de alcanzar. Habermas advierte que los individuos no se ajustan plenamente a esa racionalidad comunicativa, por tanto lo plantea como un horizonte normativo. He querido detenerme en ello para destacar el carácter normativo de la definición reconstructiva de la legitimidad. El problema reside ahora en precisar en qué sentido Habermas considera a su definición como una alternativa frente a las definiciones normativas de la legitimidad.

Creo que es posible aceptar que la definición de Habermas representa efectivamente una alternativa frente a las nociones tradicionales de la legitimidad. Su carácter alternativo se encuentra en la estrategia de fundamentación del nivel normativo. El método reconstructivo le permite a Habermas desechar el supuesto de un orden trascendente (divino, natural o histórico) como fundamento de las normas morales. De manera más precisa podemos decir que Habermas nos ofrece un criterio racional para juzgar críticamente la dimensión normativa inscrita en los procesos de legitimación. Este criterio es independiente de loś mitos, religiones, visiones del mundo, etc. que aparecen en los diversos procesos de legitimación tradicionales; ya que se trata de un principio normativo que hace referencia al carácter "formal" o estructural del discurso.

Habermas considera que la definición reconstructiva de la legitimidad también es una opción en el sentido de que no propone a priori un tipo específico de organización política. Debemos advertir aquí que la institucionalización de la idea de formación discursiva de la voluntad colectiva parece estar ligada necesariamente a una organización democrática del poder. Por ello alguien puede objetar que en la definición reconstructiva de la legitimidad sí hay una toma de partido a priori por un modelo específico de organización política. Sin embargo, Habermas mantiene que la democracia está definida esencialmente por un principio racional de legitimación y no por tipos específicos de organización. "La democratización no puede significar una preferencia apriorística por un determinado tipo de organización, en pro, por ejemplo, de la llamada 'democracia de identidad'... La discusión entre los representantes de una teoría normativa de la democracia por una parte y los de un concepto 'realista' o empírico de la misma por otra reviste unos caracteres igual- 
Enrique Serrano

mente difíciles. Si las democracias se diferencian de otros sistemas de dominación por un principio racional de legitimación, y no por tipos de organización caracterizados apriorísticamente, las críticas que entre sí se formulan unos y otros han de malograr su objetivo." ${ }^{17}$

El sentido de esta noción de la democracia lo podemos comprender mejor si tomamos en cuenta que es el resultado de una polémica con aquéllos que reducen la democracia a una serie de procedimientos. Habermas subraya que los procedimientos sólo adquieren una fuerza legitimadora en la medida en que se encuentran vinculados a una dimensión normativa. "Pero un procedimiento sólo puede legitimar indirectamente, es decir, remitiendo a instancias que por su parte tienen que ser reconocidas. Así, las constituciones burguesas escritas contienen un catálogo de derechos fundamentales, enérgicamente inmunizados contra los cambios, que posee fuerza legitimadora en la medida y sólo en la medida en que se lo entiende en conexión con una ideología aneja al sistema de dominación." ${ }^{18}$ En efecto, la implementación de procedimientos políticos hace referencia siempre a un sistema de normas que son consideradas como válidas. Pensemos, por ejemplo, en la regla de la mayoría que define los procesos electorales; sólo una descripción empírica estrecha puede hacer a un lado su relación con el valor de la "soberanía popular".

Ahora bien, así como los procedimientos democráticos nos remiten a un nivel normativo, los valores democráticos nos remiten a una serie de

17 Habermas, $R M H$, p. 252-253. RHM, p. 279-280. "Por consiguiente, la democracia, en tanto que principio de ordenación política, no particulariza a priori ningún tipo específico de organización (por ejemplo, un sistema de soviets) como el correcto. Ni tampoco excluye a priori ninguna organización que implique representacuón, delegación, etc. La cuestión es, más bien, encontrar en cada conjunto concreto de circunstancias mecanismos institucionales que justifiquen la presunción de que las decisiones políticas básicas contarían con el acuerdo de todos los afectados por ellas mismas si pudieran participar sin restricciones en una formación discursiva de la voluntad coleçtiva. Este principio sirve de estándar a la teoría crítica de la sociedad." MacCarthy, Op. cit., p. 384.

${ }^{18}$ Habermas, La lógica de las ciencias sociales, Tecnos, Madrid, 1988, p. 384. 
LEGITIMIDAD Y DISCURSO PRÁCTICO procedimientos. Podemos distinguir analíticamente entre el nivel de justificación de la dominación y los procedimientos de organización de la misma, pero entre ellos existe una mutua dependencia. A esto es muy importante tenerlo en cuenta, porque en la historia han existido regímenes que apelan a los valores democráticos, pero que no implementan los procedimientos democráticos de decisión. Ello ha conducido a dictaduras que se ejercen en nombre del "pueblo", de la "voluntad general", de la "clase universal", etc. La confusión en todas ellas consiste en querer conciliar los principios democráticos con la idea de "identidad". La única democracia viable es la que asume el carácter plural de nuestras sociedades.

Creo que se puede llegar a un acuerdo con la posición de Habermas al afirmar que la democracia no es un tipo de organización política a la manera de los modelos utópicos, empeñados en diseñar todos los aspectos de la organización social y dominados por el principio de la "identidad" o de la reconciliación plena de los conflictos sociales. La noción de democracia se encuentra ligada, sin embargo, a ciertos principios de organización política, los cuales permiten vincular su aspecto normativo con la realidad social. División de los poderes, procesos electorales competitivos, garantías institucionales a la libertad de opinión, organización, etc., son algunos de los rasgos esenciales de una organización democrática. Estos principios democráticos generales pueden encarnar en diferentes formas y ellos implican también una búsqueda continua de nuevos tipos de organización y mecanismos de participación política. Podríamos decir que la democracia presupone una organización social "abierta", esto es, en continua transformación, como consecuencia del ejercicio de la libertad.

Pero me parece apreciar que cuando Habermas califica a la definición reconstructiva de la legitimidad como una "tercera" posibilidad (frente a las definiciones empíricas y normativas tradicionales) no se refiere únicamente a los problemas metodológicos y organizativos, sino que su pretensión va más allá. Esto se puede ver cuando Habermas habla de la situación ideal de habla. "La anticipación de una situación ideal de habla tiene para toda comunicación posible el significado de una apariencia constitutiva que, a la vez, es manifestación de una forma de vida. Pero 
Enrique Serrano

no podemos saber a priori si esa ilusión, proviene, sin embargo, de suposiciones inevitables, o si pueden crearse prácticamente las condiciones empíricas para una realización (aunque sea aproximativa) de la forma de vida que esas suposiciones nos permiten poner de manifiesto. Desde este punto de vista las normas fundamentales del habla racional incluidas en la pragmática universal contienen una hipótesis práctica."19

La dificultad se localiza cuando la situación ideal de habla no se toma únicamente como una suposición contrafáctica (proveniente de suposiciones inevitables) que nos sirve como referente normativo en la crítica a los consensos fácticos, sino que se presenta como una situación en la que se anticipa una forma de vida que puede llegar a realizarse. Aquí se introduce implícitamente el supuesto de la posibilidad de acceder a una situación social donde las relaciones entre los individuos y lạ relación del individuo consigo mismo se tornen transparentes, lo cual permitiría un acuerdo pleno. Sobre este punto Wellmer observa: "Me parece que el concepto de comunicación libre de dominio, como Habermas lo construye, contiene el supuesto de que los problemas prácticos (morales-E.S.) tienen una unívoca solución racional -aún cuando nosostros podamos perderla o a causa de obstáculos internos o externos a la comunicación nos sea impedido acceder a la solución racional de los problemas. Habermas justifica este supuesto, en tanto él como medida de las soluciones concretas de los problemas prácticos no introduce un orden racional con carácter ontológico, sino el propio consenso libre de los individuos. Yo creo que en este pensamiento existe un círculo. ${ }^{20}$ En efecto, parece caerse en un círculo al pensar que el consenso racional nos permite encontrar una solución a nuestros problemas prácticos y, al mismo tiempo, creer que esa solución práctica es la posibilidad de acceder a un consenso racional.

El origen de este círculo vicioso se encuentra en la itnerpretación de la situación ideal de habla como la anticipación de una forma de vida. En la base de esta interpretación se encuentra el supuesto de una posible reconciliación (entre los hombres y entre la naturaleza "externa" e

19 Habermas, "Wahrheitstheorien", p. 181-182.

${ }^{20}$ Wellmer, A., Ethik un Dialog, Suhrkamp, Frankfurt, 1986, p. 198. 
LEGITIMIDAD Y DISCURSO PRÁCTICO "interna") en base a una solución racional unívoca de nuestros problemas prácticos-morales, a la que se accedería mediante un diálogo pacífico. En ello se percibe la sombra de la tradición utópica, en especial de la que va de $\operatorname{Marx}^{21}$ a Adorno. Esta herencia de la tradición utópica parece contradecir $\mathrm{o}$, por lo menos, entrar en conflicto con la noción "posmetafísica" ("posconvencional") de la razón que Habermas se propone desarrollar.

La tensión entre la noción de una razón "posmetafísica" y la tradición utópica no se encuentra en determinar hasta qué punto se puede realizar una organización racional de la sociedad, en la que la libertad de cada uno pueda coexistir con la de los demás. En esto ya advertía Kant lo siguiente: "Pues cuál pueda ser el grado máximo en que la humanidad haya de detenerse, y cuán amplia la distancia que necesariamente haya de quedar entre la idea y su realización, nadie puede ni debe determinarlo precisamente; porque es la libertad la que puede franquear cualquier límite indicado." 22 La dificultad entre la noción posmetafísica de la razón y la tradición utópica reside en el ideal utópico mismo, es decir, en plantear la realización de un sentido pleno, el cual otorgaría una solución racional unívoca a todos nuestros problemas en una situación de plena reconciliación. "Quien sueña con una supresión del poder hace referencia, implícitamente, a lo idéntico. ${ }^{23} \mathrm{El}$ ideal de la "identidad", que subyace a la tradición utópica, no puede compaginarse con una definición de la razón abierta a la pluralidad.

En este punto hay que tener cuidado. No se trata de afirmar simplemente que en Habermas se da un renacimiento de la filosofía de la historia y su ideal utópico de una reconciliación. Este autor es consciente de las dificultades que enfrentan las filosofías de la historia y toma frente a ellas una distancia crítica. De esta manera, él puede superar muchos de los errores de esas filosofías. Habermas no sostiene, por ejemplo, la

21 Zimmermann, Rolf, Utopie-Rationalität-Politik, Verlag Karl Albert, Feiburg/München, 1985.

${ }^{22}$ Kant, Kritik der reinen Vernunft, Suhrkamp, Frankfurt, 1974, Tomo I, p. 324 (a-317).

${ }^{23}$ Habermas, Rödel, U; Frankenberg, G; Dubiel, H. Die demokratische Frage, Suhrkamp, Frankfurt, 1989, p. 125. 
Enrique Serrano

existencia de un proceso causal regular en la historia. También reconoce que la posible "evolución" tiene costos y que con ellos aparecen nuevos problemas. "La dialéctica del progreso se manifiesta en el hecho de que, con la adquisición de capacidades para resolver problemas, se alcanza conciencia de la existencia de problemas nuevos... El sufrimiento a causa de las contingencias de un proceso que no podemos dominar gana una cualidad nueva en la medida en que nos atribuimos la facultad de intervenir en él de un modo racional. Desde el punto de vista negativo, este sufrimiento es el de una necesidad nueva. Podemos, así, hacer el intento de interpretar la evolución social en función de aquellos problemas y necesidades que se manifiestan a través de los adelantos evolutivos: el propio proceso evolutivo-social de aprendizaje genera nvevos recursos en cada etapa de desarrollo que, a su vez, suponen la existencia de dimensiones nuevas de la escasez y, con ello, necesidades históricas nuevas." 24

En la teoría de Habermas tampoco se acude a la idea de un "macrosujeto" al estilo de las filosofías de la historia tradicionales. Por el contrario, se habla de una dimensión intersubjetiva como base de la acción comunicativa, lo cual implica la pluralidad de sujetos. "La idea de un sujeto de la historia que se crea a sí mismo, era y es una ficción; pero en modo alguno es absurda la intención que esa idea a la vez expresa y yerra, de ligar la evolución de los sistemas socioculturales al tipo de control que es la autorreflexión en el sentido de una institucionalización políticamente eficaz de discursos (de comunidades intersubjetivas de orden superior autogeneradas por vía discursiva). ${ }^{25}$ De ahí la importancia de realizar un esfuerzo hermeneútico para comprender la intención de Habermas al proponer una teoría de la evolución social de los sistemas culturales.

Habermas mantiene, desde sus primeros trabajos, la necesidad de retomar la perspectiva de una "filosofía de la historia con intención práctica". Esto es, pensar a la historia no únicamente como una acumulación de sucesos, sino buscar en ellos un sentido que permita apoyar

${ }^{24}$ Habermas, RMH, p. 167.

${ }^{25}$ Habermas, La lógica..., p. 450. 


\section{LEGITIMIDAD Y DISCURSO PRÁCTICO}

nuestra práctica, como crítica del presente. ${ }^{26}$ El punto de partida de la teoría de la evolución social de Habermas es una "reconstrucción del materialismo histórico". "Reconstrucción" significa aquí una crítica interna al materialismo histórico, con la finalidad de acceder a un planteamiento más adecuado para los objetivos que esa misma teoría se había planteado.

Lo que se critica del marxismo es su concepción unilateral del desarrollo histórico de las sociedades. Para Habermas la evolución social no se puede reconstruir siguiendo únicamente la perspectiva de la organización de la fuerza de trabajo. Es por ello que Habermas se remite a los trabajos del joven Hegel para distinguir dos dimensiones de la dinámica social: "trabajo" e "interacción". 27 Por "trabajo" se entiende una acción que se guía por una racionalidad con arreglo a fines. Ésta puede adquirir el carácter de una "acción instrumental", cuando se orienta por reglas técnicas en relación a objetos del mundo externo, o el carácter de una "acción estratégica", cuando se orienta por ciertas reglas de preferencia imperantes en un contexto en relación con otros individuos. "Las acciones instrumentales de los distintos individuos muestran una racionalidad final, esto es: están coordinadas en relación con el fin productivo. Las reglas de la acción estratégica, según las cuales se produce la cooperación, son una parte componente necesaria del proceso de trabajo:"28

Mientras que por "interacción" se entiende una acción que se orienta

${ }^{26}$ Kant proponía una "paz perpetua" como horizonte normativo de la filosofía de la historia con intención práctica. Por su parte, Hegel trató de demostrar que esa reconciliación futura tiene una base objetiva en el propio debenir histórico. (Curiosamente Hegel vuelve a la perspectiva del Estado-nación como forma definitiva de esa reconciliación). Marx retoma la posición de Hegel y afirma que su mérito no es destacar la existencia de una lucha de clases, sino "mostrar" que esa lucha conduce "necesariamente" a una sociedad comunista. Entre la posición de Kant y la hegeliano-marxista se abre un abismo en el que se mueve continuamente Habermas.

27 Habermas, "Arbeit un Interaktiom", Bemerkungen zu Hegels Jenenser 'Philosophie des Geistes', Technik un Wissenschaft als 'Ideologie', Suhrkamp, Frankfurt, 1969. Ciencia y técnica como 'ideología', Tecnos, Madrid, 1984.

${ }^{28}$ Habermas, RMH, p. 133. 


\section{Enrique Serrano}

a través de normas intersubjetivamente vigentes, las que son reconocidas como tales y definen así expectativas recíprocas de comportamiento. "Ahora bien: los medios de vida no se producen con el fin de consumirlos. Al igual que el trabajo, también la distribución de los productos del trabajo está organizada socialmente. Las reglas de la distribución no se refieren a la elaboración de material o a la aplicación, adecuadamente coordinada, de los medios, sino a la vinculación sistemática de aspiraciones o intereses recíprocos. El reparto de productos acabados requiere, por tanto, unas reglas de interacción que se pueden desligar de las situaciones concretas y establecer con carácter duradero como normas reconocidas o como reglas de la acción comunicativa en el nivel de la comprensión lingüística." 29

En base a estas dos modalidades de la acción Habermas diferencia dos tipos de integración social:

1) La integración del sistema, que corresponde al trabajo. Por ella la sociedad se conserva dentro de ciertos límites, respondiendo a los problemas que le presenta su entorno mediante mecanismos impersonales (como lo es, por ejemplo, el mercado). En ella se busca un equilibrio social con independencia del consenso normativo de los individuos que intervienen en ella.

2) La integración social que corresponde a la interacción. En ella se crea un "marco institucional" sustentado en un consenso normativo de los individuos, originado en un proceso comunicativo. "La introducción de formas nuevas de integración social (por ejemplo, la sustitución del sistema de parentesco por el Estado) requiere un conocimiento de carácter práctico-moral, no un conocimiento técnico-valorativo que se pueda realizar en las reglas de la actuación instrumental y estratégica; esta sustitución no precisa de una extensión de nuestra capacidad de control sobre la naturaleza exterior, sino de un conocimiento que se materializa en las estructuras de interacción. En una palabra: una extensión de la

${ }^{29}$ Habermas, RMH, p. 133. 


\section{LEGITIMIDAD Y DISCURSO PRÁCTICO}

autonomía social frente a la naturaleza interior, que nos es propia. ${ }^{30}$

Estas dos dimensiones o niveles de la integración social están vinculadas en la dinámica social. La forma en que ellas se vinculan es a lo que Habermas denomina "principios de organización". En las llamadas sociedades tradicionales, por ejemplo, la integración del sistema se encuentra subordinada al "marco institucional" de la integración social. "Las 'sociedades tradicionales' sólo pueden subsistir mientras la evolución de los subsistemas de la acción con respecto a fines se mantiene dentro de los límites de la eficacia legitimadora de las tradiciones culturales. Ésta da lugar a una 'superioridad' del marco institucional, superioridad que ciertamente no excluye restructuraciones inducidas por un potencial excedente de las fuerzas productivas, pero que sí excluye la disolución crítica de la forma tradicional de legitimación. Esta inatacabilidad representa un buen criterio de demarcación de las sociedades tradicionales frente a las que han cruzado el umbral de la modernización.".31

En cambio el principio de organización de las sociedades capitalistas se caracteriza porque la integración del sistema (encarnada en el mercado y los sistemas administrativos) rompe con los límites del "marco institucional". El modo de producción capitalista permite una expansión permanente de los sistemas de acción con arreglo a fines. Esto es lo que percibían tanto Marx como Weber. "La superioridad de la forma de producción capitalista estriba en los dos casos siguientes: en la instauración de un mecanismo económico que garantiza a largo plazo la ampliación de los subsistemas de acción racional con arreglo a fines y en la creación de una legitimación económica bajo la que el sistema de dominación puede adaptarse a las nuevas exigencias de racionalidad que comparta el progreso de esos subsistemas. Es ese proceso de adaptación lo que Max Weber entiende como 'racionalización". 32

Habermas sostiene que en las sociedades capitalistas también hay una evolución en el nivel de la integración social. Su teoría de la evolución

\footnotetext{
${ }^{30}$ Habermas, RMH, p. 147.

${ }^{31}$ Habermas, Technik..., p. 67. Ciencia..., p. 73.

32 Habermas, Technik..., p. 70 . Ciencia..., p. 77.
} 


\section{Enrique Serrano}

social busca asumir la perspectiva de los dos niveles de integración, para ofrecer un diagnóstico sobre el desarrollo de las sociedades capitalistas. De esta manera, se busca, además, superar la unilateralidad presente en las teorías de Marx y de Weber. "La respuesta que propongo implica que el género humano en cuanto tal no aprende solamente en la dimensión del conocimiento técnicamente valorable-decisivo para la expansión de las fuerzas productivas-sino también en la dimensión de la conciencia práctico-moral -fundamental para las estructuras interactivas." ${ }^{33}$

Para conceptualizar el proceso de aprendizaje en el nivel práctico-moral Habermas acude, en un primer momento, al modelo del psicoanálisis y, posteriormente, al modelo de la psicología evolutiva de signo cognoscitivo (Piaget y Kohlberg). Ello resulta problemático, porque implica extrapolar los modelos psicológicos de socialización del individuo a la explicación del desarrollo de las estructuras normativas de la sociedad. En la base de esta extrapolación se encuentra la poco afortunada analogía entre ontogénesis y filogénesis, la cual ha sido uno de los temas favoritos de la filosofía y de la historia tradicionales. El propio Habermas advierte los peligros y dificultades que se esconden detrás de esta analogía; sin embargo, él insiste en usar estos modelos para dar cuenta de la racionalización cultural de las sociedades.

"Toda teoría general de la justificación permanece característicamente abstracta frente a las formas históricas de la dominación legítima. Aplicar raseros de justificación discursiva a sociedades tradicionales es comportarse de modo históricamente 'injusto'. ¿Hay una alternativa a esa injusticia histórica de las teorías generales por una parte, y a la arbitrariedad de la mera comprensión histórica por otra? El único programa con perspectivas que acierto a ver lo constituye una teoría que aclare estructuralmente la sucesión históricamente observable, de niveles de justificación y la reconstruya como un contexto lógico-evolutivo. La bien probada psicología evolutiva de signo congnoscitivo, que ha reconstruido, en lo relativo a la ontogénesis, las etapas de la conciencia moral, puede al menos entenderse como una indicación heurística y como un aliento." ${ }^{34}$

${ }^{33}$ Habermas, $R M H$, p. 149.

${ }^{34}$ Habermas, $R M H$, p. 171-172. ¿No es acaso una mayor injusticia reducir todas 
LEGITIMIDAD Y DISCURSO PRÁCTICO

Es curioso que Habermas haya retomado del jovel Hegel la distinción entre trabajo e interacción y no haya, al mismo tiempo, recuperado el principio de la "lucha por el reconocimiento" para dar cuenta del proceso de racionalización cultural. "Hegel atribuye el proceso de aprendizaje moral de la especie a la experiencia negativa de la lucha práctica, en la que los sujetos sostienen una lucha por su reconocimiento jurídico y social. Con ello Hegel anticipó una crítica materialista a las teorías del desarrollo cognoscitivas. De un concepto transformado de lucha social puede también beneficiarse una teoría social crítica, porque ese concepto abre la posibilidad para esa teoría de interpretar el proceso histórico como consecuencia de conflictos y enfrentamientos morales. ${ }^{.35}$ En efecto, para Hegel los conflictos sociales no se reducen a un problema de distribución de los bienes sociales, sino que implican una dimensión moral: la lucha por el derecho a tener derechos (el reconcomiento como persona). Desde este punto de vista la explicaicón de la racionalización de las estructuras normativas de la sociedad nos remite directamente a la historia de las luchas sociales y su influencia en el marco institucional y no a un proceso psicológico.

Es cierto que el concepto de "lucha por el reconocimiento" requiere, como sostiene Honneth, ser transformado para poder ser utilizado por una teoría crítica. Creo que una de las transformaciones más importantes de este concepto debe estar dirigida a romper el vínculo que existe en el sistema hegeliano entre esta lucha con una filosofía de la historia. La "lucha por el reconocimiento" no tiene un "origen", ni un "final", sino que la debemos entender como un principio abstracto que aparece en toda forma de asimetría social. En cada una de las formas de asimetría social "la lucha por el reconocimiento" adquiere un carácter específico. La manera en que se desenvuelve esta lucha en el nivel de la socialización de los individuos es, por ejemplo, diferente al modo en que se desarrolla

las modalidades de legitimación a eslabones en una cadena evolutiva? ¿No es una mayor injusticia desechar la especificidad de los diversos sistemas políticos a favor de una continuidad histórica?

${ }^{35}$ Honneth, A., "Moralische Entwicklung und sozialer Kampf". Zwischenbetrachtungen in Proze $\beta$ der Aufklärung, Suhrkamp, Frankfurt, 1989. Kritik der Macht, Suhrkamp, Frankfurt, 1989. 
Enrique Serrano

en la relación sociedad civil-Estado, etc. Recuperar el concepto de "lucha por el reconocimiento" puede servir además para establecer una mediación entre "trabajo" e "interacción" ("mundo de la vida"y "sistema"), así como para realizar una crítica radical a la noción funcionalista de poder (poder como "medio").

Los modelos evolutivos construidos a partir de la psicología nos ofrecen pautas de desarrollo poco flexibles, lo cual las hace inadecuadas para conceptualizar el desarrollo de las estructuras normativas de la sociedad. El "modelo Freud" nos presenta la emancipación del género humano en términos de autorreflexión y el "modelo Piaget" ${ }^{16}$ en términos de una lógica evolutiva que debe cumplir gradualmente con diferentes etapas de aprendizaje. En ambos casos se pierde la especificidad de la dimensión política y su apertura de posibilidades que no obedecen a una pauta prestablecida. Es cierto que Habermas no pasa por alto la presencia del conflicto social, pero con los modelos psicológicos parece subordinarlo a una lógica evolutiva situada por encima de él. ¿Se trata acaso de postular nuevamente la acción de una astuta razón que "usa" el conflicto como medio para cumplir sus fines? Por otra parte, la extrapolación de la psicología evolutiva nos acerca demasiado, a pesar de todas las precauciones que toma Habermas, a la idea de un sentido histórico que "debe" cumplirse.

Si queremos captar la especificidad del desarrollo de las estructuras normativas de la sociedad tendremos que volver al medio en el cual éstas se desenvuelven, a saber: el conflicto social. Mi propuesta es pensar el desarrollo de las estructuras normativas no como una "lógica evolutiva", sino a través de una vía negativa, esto es, como el cuestionamiento de las pseudouniversalidades o particularidades que pretenden adquirir un estatuto universal o que reprimen una perspectiva universalista. Precisamente la lucha por el reconocimiento podemos pensarla como un enfrentamiento las pseudouniversalidades. Esto nos acercaría al devenir histórico empírico, pues nos permitiría abordar el estudio de las luchas sociales no sólo desde la perspectiva de la redistribución de la riqueza, sino también en su sentido moral y jurídico. La lucha de individuos o

${ }^{36}$ Wellmer, "Über Vernunft, Emanzipation und Utopie", Op. cit. 
LEGITIMIDAD Y DISCURSO PRÁCTICO grupos que buscan su reconocimiento como "personas" y como tal cuestionan la pretendida universalidad de un orden establecido (reconocimiento que no sólo puede pensarse en términos formales). Pensemos en las luchas obreras, feministas, de minorías raciales, etnias, etc.

Es posible asumir los logros de las investigaciones psicológicas, sin tener que aceptar la conceptualización del desarrollo de las estructuras normativas de la sociedad como un proceso psicológico. Se puede relacionar la perspectiva ontogenética y la filogenética sin establecer entre ellas una analogía. Ello nos permitiría, además, recuperar los resultados de la ciencia antropológica (entendida como sociología de "otras" culturas). El logro más destacado de estas disciplinas es el reconocimiento de que los "otros", llamados "salvajes" o "pueblos primitivós", no son niños ingenuos, ni "buenos" (o "malos"), ni individuos que se encuentran en una etapa "prelógica", sino que representan simplemente otra forma de conceptualizar el mundo. Si acaso se puede hablar de una evolución de las estructuras normativas es, precisamente, en la capacidad de reconocer a los "otros", para aprender de ellos a percatarnos de nuestra propia unilateralidad. Es decir, aprender que la vida se puede racionalizar desde las más diversos puntos de vista. Esto no puede calificarse, desgraciadamente, ni como una enseñanza generalizada ni definitiva de nuestra cultura (en cualquiera que nos situemos).

En la Teoría de la acción comunicativa Habermas denomina este desarrollo como "decentración de las imágenes del mundo". "La evolución cognitiva significa en términos generales la decentración de una comprensión del mundo de cuño inicialmente egocentrista. ${ }^{37}$ Pero al utilizar los términos de la psicología evolutiva se presta a una confusión sobre el carácter de este desarrollo social.

No debemos perder de vista que la llamada "decentración de las imágenes del mundo" es el resultado de los conflictos sociales y que éstos sólo pueden objetivarse en un desarrollo histórico si se cumplen por lo menos estas dos condiciones: 1 . Un cierto equilibrio de poder entre las fuerzas sociales y 2. la transformación de ese equilibrio en una nueva forma de institucionalización de las relaciones de poder y por tanto en

${ }^{37}$ Habermas, TKH, Tomo I, p. 106. TAC, Tomo I, p. 103. 


\section{Enrique Serrano}

una nueva forma de ejercicio del poder. En este sentido me parece importante rescatar laintuición de Weber de estudiar el desarrollo de las imágenes del mundo en dos niveles: A) El de la relación entre las imágenes del mundo y las relaciones de poder y conflictos sociales. B) El de la lógica y dinámica de esas visiones del mundo. Hacer a un lado cualquiera de estos niveles es caer en la unilateralidad.

Es evidente que Habermas puede responder que la institucionalización de las nuevas relaciones de poder requiere de un nuevo nivel de las estructuras normativas de la sociedad. "Incluso quisiera sostener la tesis de que el desarrollo de estas estructuras normativas representa la avanzadilla de la evolución social, pues nuevos principios de organización social significan nuevas formas de integración social, y sólo éstas, por su parte, hacen posible la implementación de las fuerzas productivas existentes o la generación de otras nuevas, así como el incremento de la complejidad de la sociedad. ${ }^{138}$ Ante ello habría que preguntar: ¿Qué es primero, la transformación de las formas de ejercicio del poder o la transformación de las estructuras normativas? Me parece que si realmente se quiere superar la unilateralidad de la teoría marxista del desarrollo social hay que renunciar a las explicaciones causales simples.

Cuando afirmamos que se trata de explicar el desarrollo de las concepciones del mundo a través de una vía negativa, implica renunciar a la idea de una "evolución lógica" hacia una universalidad en la que se abren las puertas del entendimiento pleno (identificado con la "Verdad"). Se trata, como hemos dicho, de abordar el desarrollo social como un cuestionamiento permanente de las falsas universalidades. Esta crítica a las pseudouniversalidades se desencadena en el interior de los conflictos sociales, los cuales se desenvuelven tanto en la integración social como en la integración del sistema. Entre estos dos niveles existe una relación compleja (no olvidemos que se trata de una distinción analítica), irreductible a un vínculo causal simple. El proceso de desarrollo social no presupone necesariamente ningún punto culminante; ni tampoco la realización de un modelo de sociedad transparente. El desarrollo de las estructuras normativas no conduce a un entendimientó pleno o en su

${ }^{38}$ Habermas, RMH, p. 35. 
LEGITIMIDAD Y DISCURSO PRÁCTICO sentido máximo, sino a un entendimiento sobre la forma de enfrentar nuestros conflictos, que garantice tanto la integridad de la sociedad, como la integridad de cada uno de sus miembros.

Habermas en la Teoría de la acción comunicativa asume que la racionalidad comunicativa, entendida como el resultado de una comprensión decentrada del mundo, tiene un carácter procedimental y que, por tanto, de ella no es posible obtenerse el ideal de una forma de vida plenamente racional. $^{39}$ El propio Habermas califica al utopismo que confunde la ifnraestructura comunciativa con una forma de vida lograda como un error de la modernidad. Esto último nos permite llegar a un acuerdo fundamental, al permitir eliminar la ambigüedad del concepto de situación ideal del habla. Se tiene que aceptar que este concepto no presupone ninguna anticipación de una forma de vida ("lograda"), sino que sólo es un criterio normativo.

Por otra parte, esto también nos permite confirmar que la definición reconstructiva de la legitimidad no es una "tercera" alternativa, sino sólo un criterio para juzgar críticamente los consensos fácticos que sustentan las diversas formas de legitimación. La definición reconstructiva de la legitimidad tiene, entonces, que asumir la definición empírica de la legitimidad como punto de partida, sin presuponer una forma de legitimación "auténtica" o "verdadera" en que las relaciones de poder queden superadas. Su potencialidad crítica no se encuentra en anticipar una utopía de la reconciliación, sino en sustentar las críticas concretas a las diversas formas de legitimación. "Nosotros no podemos anticipar la perfección del sentido, sino sólo la eliminación del sinsentido. Nosostros no podemos pensar las relaciones entre los individuos completamente libres de toda coacción, ni una racionalidad plena, pero de hecho podemos intentar suprimir y a partar las coacciones y bloqueos que experimentamos." ${ }^{40}$

Con esta serie de observaciones críticas he querido llamar la atención sobre la tensión que existe en la teoría de Habermas entre la noción posmetafísica de la razón y la situación ideal del habla, entendida como

\footnotetext{
${ }^{39}$ Habermas, TKH, p. 110-113. TAC, p, 107-109.

${ }^{40}$ Wellmer, Op. cit., p. 220.
} 


\section{Enrique Serrano}

la anticipación de una forma de vida realizable. Habermas es consciente de esta tensión y de las dificultades que ella engendra. Creo que en la base de los cambios y modificaciones de su teoría se encuentra un intento de superar estas dificultades y no existe, hasta la fecha, una toma de posición definitiva ante este problema. No debemos olvidar que se trata de una filosofía viva. Con ello no me refiero únicamente al hecho de que Habermas esté vivo sino también a que se trata de una filosofía abierta, por principio, a la discusión y, por tanto, a la transformación.

Mientras tanto, por nuestra parte, podemos rescatar el principio de la "prohibición de las imágenes" (Bildverbot) que caracterizaba ala primera escuela de Frankfurt. Esta prohibición de imágenes se convertia en un rechazo de toda utopía positiva, lo cual dejaba como única alternativa la crítica a las formas de dominación concretas que se nos dan en el presente, así como la crítica a sus pretensiones de ser formas definitivas de la historia. ${ }^{41}$ Cuando la Teoría Crítica afirmaba "hay algo más", no se trataba de definir ese algo, sino destacar las contradicciones en las formas de organización del presente. No se trata de anunciar la realización del sentido pleno, sino denunciar y enfrentar el "sinsentido" en el presente.

41 Desgraciadamente la Escuela de Frankfurt no continuó con este proyecto. Como apunta George Friedman, la escuela de Frankfurt estaba lo suficientemente cerca de la tradición del judaísmo para retomar la esperanza de una redención, pero no lo suficiente para mantener esa esperanza dentro de la crítica al presente. Por ello se abandonaron a la idea de una reconciliación abstracta y a la desesperanza ante una realidad que se alejaba de ese ideal. "La Escuela de Frankfurt es, por último, más digna de alabanza por lo que no pudo realizar porque, en su fracaso, demostró la bancarrota de la modernidad." La filosofía política de la Escuela de Frankfurt, F.C.E., México, 1986. 